\title{
Electron Probe Microanalysis and Microscopy: Focused Electron Beam Techniques and Applications in Characterization of Mineral Inclusions in Diamond
}

Donggao Zhao

Department of Geological Sciences, Jackson School of Geosciences, University of Texas at Austin, Austin, TX 78712, USA.

Electromagnetic lens-focused electron beam, commonly called electron probe, is widely used in microanalysis and microscopy [1-6]. For example, electron probe is exclusively used in a scanning electron microscope (SEM) to acquire information of samples on images at micro- to nano-scales (BSE, SE, CL, etc.), chemistry (EDS, WDS, etc.), and crystal structure (EBSD). Electron probe, not parallel electron beam, is also used in STEM mode in a transmission electron microscope (TEM) to acquire similar information of samples (bright field, dark field, HAADF, EFTEM, EDS, EELS, electron diffraction, etc.) at nano- to pico-scales. All these techniques in microanalysis and microscopy use an electron probe as primary input signal to bombard a sample; and the signals detected can come from above the sample surface (SEM) or below the sample if an electron probe penetrates through the sample (STEM). Therefore, the techniques mentioned above all belong to electron probe microanalysis and microscopy or EPMM in short. In EPMM techniques, the electron probe scans across the sample and this dynamic process is different from the static process in the parallel electron beam techniques (TEM mode).

Use EPMM techniques, a variety of silicate, carbonate and sulfide inclusions were recovered in the diamond from the No. 50 kimberlite diatreme of Liaoning Province, China (Fig. 1) [7, 8]. These inclusions include, in order of abundance, olivine, chromite, garnet, orthopyroxene, Ca carbonate, magnesite, dolomite, norsethite, pyrrhotite, pentlandite, troilite, a member of the linnaeite group, an unknown hydrous magnesium silicate and an iron-rich phase. Abundance and composition of the mineral inclusions in diamond indicate that they belong to peridotitic suite and are mainly harzburgitic. No eclogitic mineral inclusions were found in the diamond. The slightly lower Mg \# of the olivine inclusions (peak at 93) than that of harzburgitic olivine inclusions worldwide (Mg \# peak at 94), the higher Ni content (0.25-0.45 wt \%) of the olivine inclusions than those of olivine inclusions worldwide, the higher Ti contents (up to 0.79 wt \%) in some chromite inclusions in diamond than those in chromite inclusions worldwide, the existence of carbonate inclusions in diamond, and the possible presence of hydrous silicate phases in diamond all indicate a metasomatic enrichment event in the source region of diamond beneath the North China craton. Sulfide inclusions in diamond often coexist with chromite and olivine or are rich in Ni content, indicating that the sulfide inclusions belong to the peridotitic suite. From the chemical compositions, most sulfide inclusions in diamond from the No. 50 kimberlite were probably trapped as monosulfide crystals, although some may have been entrapped as melts. The pressure and temperature obtained from applicable thermobarometers indicate that the diamond crystallized in the range of $980^{\circ} \mathrm{C}$ and $45 \mathrm{kbar}$ to $1220^{\circ} \mathrm{C}$ and $69 \mathrm{kbar}$, corresponding to a depth of 140 to $200 \mathrm{~km}$.

\section{References:}

[1] J. Goldstein et al., Scanning Electron Microscopy and X-Ray Microanalysis (Third Edition). Kluwer Academic Publishers (2003). 
[2] S.J.B. Reed (2005) Electron Microprobe Analysis and Scanning Electron Microscopy in Geology (Second Edition). Cambridge University Press (2005).

[3] D.B. Williams et al., Transmission Electron Microscopy - A Textbook for materials Science (Second Edition). 822 pages. Plenum Press (2009).

[4] D.J. Cherniak et al., (2010) Analytical Methods in Diffusion Studies. Reviews in Mineralogy \& Geochemistry, vol. 72 (2010), 107-170.

[5] D. Zhao et al., Electron Probe Microanalysis and Microscopy: Principles and Applications in Characterization of Mineral Inclusions in Chromite from Diamond Deposit. Ore Geology Reviews 65 (2015), 733-748.

[6] S.N. Frelinger et al., Scanning electron microscopy cathodoluminescence of quartz: principles, techniques and applications in ore geology. Ore Geology Reviews 65 (2015), 840-852.

[7] Y. Huang et al., (1992) Kimberlites and Diamonds in the North China Craton (in Chinese), Geological Publishing House, Beijing (1992).

[8] D. Zhao, Kimberlite, diamond and mantle xenolith from Northwest Territories, Canada and North China. Ph.D. Thesis, University of Michigan.

Fig. 1. BSE images of diamond hosts and their olivine mineral inclusions. (a) Diamond LN50D03 and an elongated olivine inclusion. (b) A second polished surface of diamond LN50D03 with two euhedral olivine inclusions. (c) Two olivine inclusions and one chromite inclusion at the upper right corner in diamond LN50D04. (d) The euhedral olivine inclusion at the center of diamond LN50D04. (e) Diamond LN50D39 with an olivine inclusion. (f) One anhedral olivine inclusion in diamond LN50D44. (g) One euhedral olivine inclusion in diamond LN50D45. Note the bent feature of the inclusion

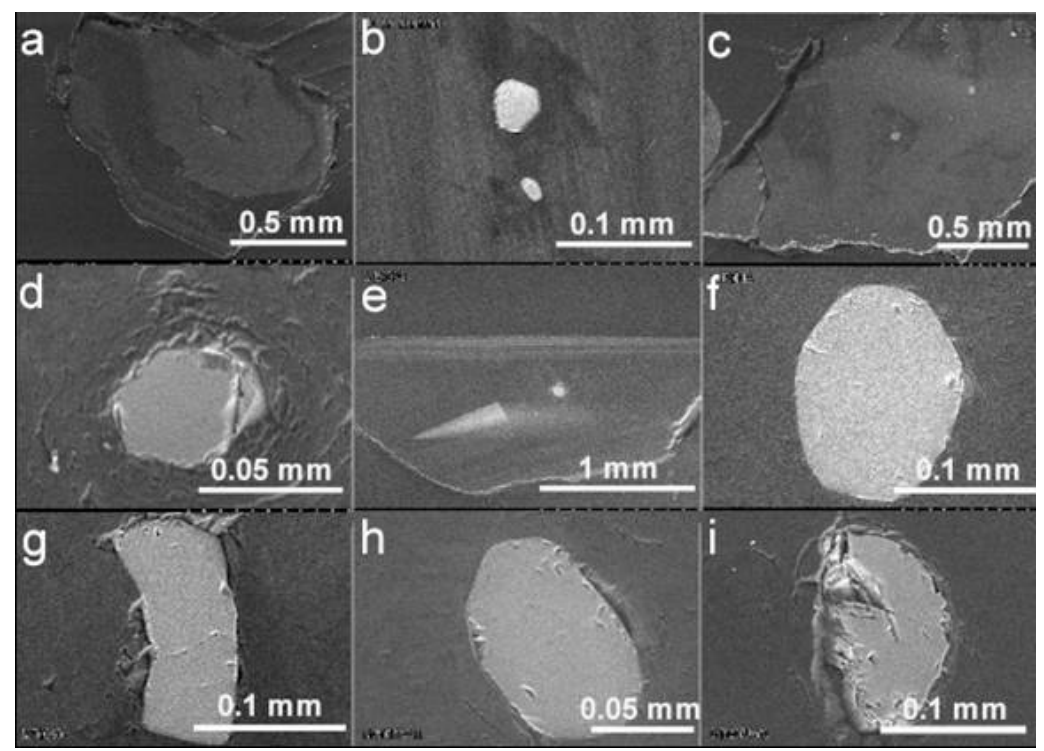
that was constrained by the crystal form of diamond host. (h) One subhedral olivine inclusion in diamond LN50D55.

(i) One elongated olivine inclusion in diamond LN50D68. 